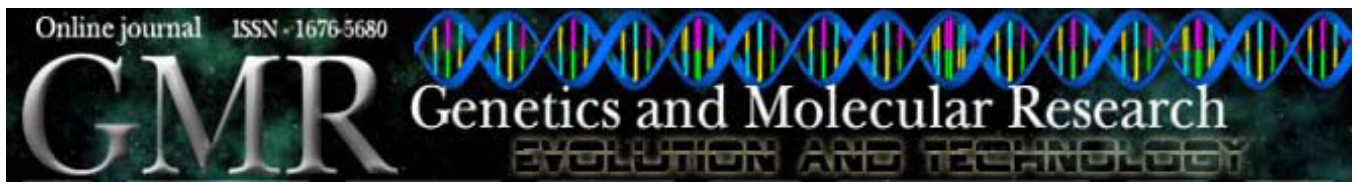

\title{
Evaluation of antimicrobial activity of endophytic fungi from Camptotheca acuminata (Nyssaceae)
}

\author{
T. Ding ${ }^{1}$, T. Jiang ${ }^{2}$, J. Zhou ${ }^{1}$, L. Xu' ${ }^{2}$ and Z.M. Gao ${ }^{1}$ \\ ${ }^{1}$ School of Plant Protection, Anhui Agricultural University, Hefei, China \\ ${ }^{2}$ School of Life Science, Anhui Agricultural University, Hefei, China \\ Corresponding author: Z.M. Gao \\ E-mail:gzm@ahau.edu.cn
}

Genet. Mol. Res. 9 (4): 2104-2112 (2010)

Received May 1, 2010

Accepted July 27, 2010

Published October 26, 2010

DOI 10.4238/vol9-4gmr809

\begin{abstract}
Agricultural research of plant-derived endophytic fungi has grown in recent decades. We isolated 26 endophytic fungi from the leaves, stems and fruits of "the tree of life", Camptotheca acuminata, and tested them for antimicrobial activities based on growth inhibition measurements in a modified agar diffusion method. Fermentation broths from most of the isolates exhibited antifungal activity and 50\% exhibited antibacterial activity; some of them also exhibited strong broad-spectrum antimicrobial activity. The strongest antimicrobial activity was exhibited by strains XSY10 and XSY15 against Rhizoctonia solani and Fusarium oxysporum f. sp. vasinfectum, with $75 \%$ and $67 \%$ inhibition, respectively. Strain XSJ01 gave strong activity against pathogenic bacteria, with inhibition zones more than $20 \mathrm{~mm}$ in diameter. The isolates were identified by molecular methods as belonging to nine taxa: Nigrospora, Diaporthe, Alternaria, Colletotrichum, Pestalotiopsis, Sordariomycete, Guignardiai, Penicillium, and Zythia. Based on
\end{abstract}


these results, we conclude that the endophytic fungi of $C$. acuminata are promising sources of novel bioactive compounds.

Key words: Camptotheca acuminata Decne.; Endophytic fungi; Antimicrobial activity

\section{INTRODUCTION}

The majority of all global agricultural production is lost each year due to various diseases and pests (Bajwa et al., 2003). Among the losses, nearly $20 \%$ is the result of pathogenic fungal diseases (Agrios, 2000). Chemical compounds are the major measure for avoiding loss of yield due to these fungi. No doubt, the use of chemicals has been effective in controlling these diseases, but there are some major problems. One problem is the tendency of pathogens to develop resistance to chemicals (Bajwa et al., 2003); another is the creation of a hazardous environment by these chemical fungicides, because of their non-biodegradable nature (Hayes and Laws, 1991). These problems highlight the need to develop alternative methods for controlling plant diseases (Arnason et al., 1989).

Endophytes are defined as fungi that colonize healthy plant tissue, and the host tissue infected is at least transiently symptomless. They are quite ubiquitous and have been found in all plant species examined to date (Arnold et al., 2000). Endophytes not only can mediate interactions between host plants and herbivores and pathogens, but can also control food-web structure by disrupting the transfer of energy from plants to upper trophic levels (Omacini et al., 2001). Hence, the endophytic fungi are expected to be a potential source of new natural bioactive products.

Camptotheca acuminata Decne. is one of the most valuable timber resources in southern China. In the last years, most research on it has been carried out in terms of some products of secondary metabolism. However, few studies have been conducted on the anti-phytopathogen activity of the endophytic community of this plant. The current study was conducted to isolate and screened for endophytic fungi with anti-phytopathogen activity from living symptomless tissues of leaves, stems and fruits of C. acuminata Decne., and also to assess the inhibitory activities of the endophytic fungi against the several important phytopathogens tested.

\section{MATERIAL AND METHODS}

\section{Plant collection}

The healthy leaves, stems and fruits of $C$. acuminata Decne. were collected at 2-month intervals from January to November 2007 from Anhui Agricultural University $\left(31^{\circ} 86^{\prime} \mathrm{N}\right.$ and $\left.117^{\circ} 25^{\prime} \mathrm{E}\right)$, Anhui Province, China. The samples were processed within $24 \mathrm{~h}$ following collection.

\section{Isolation, culture and identification}

For the isolation of endophytic fungi, healthy plant tissues were washed in run- 
ning tap water and processed as follows: samples were surface-sterilized by immersing in $95 \%$ ethyl alcohol for $1 \mathrm{~min}$, then soaked in sodium hypochlorite (5\% available chlorine) for $3 \mathrm{~min}$ and again transferred to $95 \%$ ethyl alcohol for $30 \mathrm{~s}$. Finally, the samples were rinsed three times in sterile distilled water and surface-dried with sterile filter paper. To confirm that the disinfection process was successful, aliquots of the sterile distilled water used in the final rinse were also plated onto the surface of potato dextrose agar (PDA) plates supplemented with streptomycin $(30 \mu \mathrm{g} / \mathrm{mL})$, and the plates were examined for growth after incubation at $25^{\circ} \mathrm{C}$ for 3 days.

After surface sterilization, the samples were cut into segments of approximately 3 $\mathrm{mm}^{2}$ and placed on the surface of PDA plates supplemented with streptomycin $(30 \mu \mathrm{g} / \mathrm{mL})$. The plates were then incubated at $25^{\circ} \mathrm{C}$ with normal daily light and dark periods, and checked every other day for 15 days for the development of fungal colonies growing out from the segments. Fungi growing out from the tissue were subsequently transferred to PDA plates and, when found to be pure, on agar slopes without antibiotics.

The main endophytic fungi encountered were identified using molecular tools. Genomic DNA was extracted from ground mycelium (Lee et al., 1988). Primers ITS5 5' TCCGT AGGTGAACCTGCGC 3' and ITS4 5' TCCTCCGCTTATTGATATGC 3' were used to amplify the 5.8S and flanking internal transcribed spacer (ITS) regions of the orphospecies. The DNA fragment was amplified and sequenced according to previously described methods (Guo et al., 2000). The sequence data from this study have been submitted to GenBank under accession Nos. FJ643571-FJ643589.

\section{Fermentation and treatment of the fermentation broth of endophytic fungi}

The endophytic fungi were added to $50 \mathrm{~mL}$ potato dextrose broth in Erlenmeyer flasks and incubated at $25^{\circ} \mathrm{C}$ and $160 \mathrm{rpm}$ with normal daily light and dark periods for 10 days. The mycelia of the endophytic fungi were separated by filtering with Whatman filter paper, so that the fermentation broth of each endophytic fungus was obtained and, finally, samples were dried in a freeze-drying system (FreeZone12, Labconco Ltd., USA).

\section{Microorganisms used}

The microorganisms tested were obtained from the School of Plant Protection, Anhui Agricultural University, Anhui Province, Southeast China.

\section{Growth inhibition measurements}

The antifungal activity of the fermentation broth was determined in a number of pathogenic fungi: Rhizoctonia solani, Gibberella fujikuroi, Pyricularia grisea, Gibberella zeae, and Fusarium oxysporum f. sp. vasinfectum. Prior to testing, indicator organisms were cultured in PDA medium at $27^{\circ} \mathrm{C}$.

The freeze-dried fermentation broth of endophytic fungi was dissolved in sterilized water at a concentration of $1 \mathrm{mg} / \mathrm{mL}$ and the solution sterilized by filtration with $0.22-\mu \mathrm{m}$ Millipore filters, and $0.2-\mathrm{mL}$ samples were then poured on sterile Petri dishes containing $15 \mathrm{~mL}$ 
PDA, followed by adequate mixing. A negative control was prepared using $0.2 \mathrm{~mL}$ sterilized water. For the positive controls, $50 \mathrm{mg} / \mathrm{L}$ propiconazole and $5 \mathrm{mg} / \mathrm{L}$ benomyl were used for G. fujikuroi and F. oxysporum f. sp. vasinfectum, respectively, and $100 \mathrm{mg} / \mathrm{L}$ carbendazim was used for R. solani, P. grisea and G. zeae.

A 6-mm diameter plug of the actively growing mycelium of the pathogenic fungi was placed in the center of each plate. The plates were incubated at $27^{\circ} \mathrm{C}$ in the dark $(3$ plates per treatment). The diameters of the inhibition zones were measured by vernier caliper. According to the growth rate of each fungus, colony diameter data taken after 2 days ( $R$. solani), 5 days (G. zeae, G. fujikuroi and F. oxysporum f. sp. vasinfectum), and 12 days (P. grisea) were used. The inhibitory activity of each treatment was carried out using the following formula,

$$
\text { Growth inhibition }(\%)=\left[\frac{\mathrm{DC}-\mathrm{DT}}{\mathrm{DC}}\right] \times 100 \%
$$

where $\mathrm{DC}=$ diameter of control and $\mathrm{DT}=$ diameter of fungal colony with treatment. The experiments were repeated twice and the data presented here are the averages of two experiments.

\section{Modified agar diffusion method}

The test organisms for the agar diffusion test were two bacteria, Pseudomonas solanacearum and Ralstonia solanacearum, and they were from diseased specimens of ginger and tobacco, respectively. Prior to testing, indicator organisms were cultured on nutrient agar medium at $37^{\circ} \mathrm{C}$.

The freeze-dried fermentation broth of endophytic fungi was dissolved in sterilized water at a concentration of $100 \mathrm{mg} / \mathrm{mL}$ and sterilized by filtration with $0.22-\mu \mathrm{m}$ Millipore filters. A modified agar diffusion method (NCCLS, 2003) was used to determine the antibacterial activity. A negative control was prepared using sterilized water, and nystatin (Nys, Amerisco) $(10 \mu \mathrm{g} /$ disc $)$ was used as a positive reference standard. The plates were incubated at $37^{\circ} \mathrm{C}$ for $24 \mathrm{~h}$ for bacterial strains, the diameters of the inhibition zones were measured by vernier caliper. Each test was performed in three replicates and repeated twice.

\section{RESULTS}

\section{Isolation of endophytic fungi}

A total of 26 strains were obtained from the leaves, stems and fruits of C. acuminata Decne. Among them, 21 were isolated from leaves, 3 from stems and 2 from fruits. These endophytic fungi were identified by ITS sequence analysis and belonged to 9 taxa (Table 1). 
Table 1. Taxa of endophytic fungi of Camptotheca acuminata Decne.

\begin{tabular}{|c|c|c|}
\hline Host site & Strain No. & Taxa \\
\hline \multirow{21}{*}{ Leaves } & XSY01 & Nigrospora sp 1 \\
\hline & XSY02 & Nigrospora $\mathrm{sp} 2$ \\
\hline & XSY03 & Diaporthe sp 1 \\
\hline & XSY04 & Diaporthe sp 2 \\
\hline & XSY05 & Alternaria sp 1 \\
\hline & XSY06 & Alternaria sp 2 \\
\hline & XSY07 & Nigrospora sp 3 \\
\hline & XSY08 & Diaporthe sp 3 \\
\hline & XSY09 & Diaporthe sp 4 \\
\hline & XSY10 & Colletotrichum $\mathrm{sp} 1$ \\
\hline & XSY11 & Colletotrichum $\mathrm{sp} 2$ \\
\hline & XSY12 & Diaporthe sp 5 \\
\hline & XSY13 & Pestalotiopsis sp 1 \\
\hline & XSY14 & Diaporthe $\mathrm{sp} 6$ \\
\hline & XSY15 & Sordariomycete sp \\
\hline & XSY16 & Diaporthe sp 7 \\
\hline & XSY17 & Nigrospora $\mathrm{sp} 4$ \\
\hline & XSY18 & Alternaria sp 3 \\
\hline & XSY19 & Nigrospora sp 5 \\
\hline & XSY20 & Guignardia vaccini \\
\hline & XSY21 & Colletotrichum $\mathrm{sp} 3$ \\
\hline \multirow[t]{3}{*}{ Stems } & XSJ01 & Penicillium $\mathrm{sp}$ \\
\hline & XSJ02 & Pestalotiopsis sp 2 \\
\hline & XSJ03 & Pestalotiopsis sp 3 \\
\hline \multirow[t]{2}{*}{ Fruits } & XSG01 & Zythia sp 1 \\
\hline & XSG02 & Zythia sp 2 \\
\hline
\end{tabular}

Effects of the fermentation broth of endophytic fungi on in vitro growth of pathogenic fungi

In the present study, the fermentation broths of 26 endophytic fungi were screened for antifungal activities in 5 pathogenic fungi, and the results show that the antifungal activities of the isolates were significantly different. With $R$. solani, the inhibition rate of XSY10 was $74.97 \%$ and significantly higher than that of the fungicide carbendazim $(100 \mathrm{mg} / \mathrm{L})$, whereas the strains XSY01, XSY12, XSY18, and XSY19 showed no inhibitory effect (Table 2).

The effect of the 26 endophytic fungi on the growth of $G$. fujikuroi was lower compared to the effect on $R$. solani (Table 2). The highest inhibition by XSG02 was only $43.62 \%$, which was significantly different from that of the fungicide propiconazole $(50 \mathrm{mg} / \mathrm{L})$, used as a reference. Among the 26 endophytic fungi, the inhibition of most strains varied from 6.89 to $34.98 \%$. The effect of the 26 endophytic fungi on the growth of P. grisea was similar to the effect on G. fujikuroi (Table 2). The results show that none of the treatments equaled $100 \mathrm{mg} / \mathrm{L}$ carbendazim, which was used as the positive control. None of the freeze-dried fermentation broths of the 26 endophytic fungi was able to suppress growth by $50 \%$, where the highest inhibition was only $39.63 \%$.

Among the 26 endophytic fungi, the radial growth of G. zeae was reduced by 23 strains at $1 \mathrm{mg} / \mathrm{mL}$ (Table 2). The highest inhibition by XSY03 was $47.10 \%$, which was higher than that of the fungicide carbendazim $(100 \mathrm{mg} / \mathrm{L})$. The freeze-dried fermentation broth of 23 endophytic fungi at $1 \mathrm{mg} / \mathrm{mL}$ showed antifungal activity against $F$. oxysporum $\mathrm{f}$. 
sp. vasinfectum (Table 2). XSY15 showed higher growth inhibitory effects, where the freezedried fermentation broth at $1 \mathrm{mg} / \mathrm{mL}$ caused $67.0 \%$ inhibition, compared to $61.85 \%$ for 5 $\mathrm{mg} / \mathrm{L}$ benomyl, used as the positive control.

Table 2. Effects of the freeze-dried fermentation broth of endophytic fungi on in vitro growth of pathogenic fungi.

\begin{tabular}{|c|c|c|c|c|c|}
\hline \multirow[t]{2}{*}{ Part tested ${ }^{a}$} & \multicolumn{5}{|c|}{$\%$ Growth inhibition } \\
\hline & R. solani & G. fujikuroi & P. grisea & G. zeae & $\begin{array}{c}\text { F. oxysporum } \\
\text { f. sp. vasinfectum }\end{array}$ \\
\hline \multicolumn{6}{|l|}{ Leaves } \\
\hline XSY01 & $-0.13^{i \mathrm{jklm}}$ & $8.10^{\mathrm{k} \mathrm{k}}$ & $-2.95^{\mathrm{ijk}}$ & $24.79^{\text {cd }}$ & $-1.98^{\circ}$ \\
\hline XSY02 & $4.48^{\mathrm{hijklm}}$ & $11.00^{\mathrm{jk} k}$ & $1.36^{\mathrm{gh}}$ & $5.39^{\mathrm{gh}}$ & $9.90^{\mathrm{ij}}$ \\
\hline XSY03 & $8.43^{\text {ghij }}$ & $12.51^{\mathrm{h}}$ & $-1.40^{\mathrm{hijk}}$ & $47.10^{\mathrm{a}}$ & $8.25^{\mathrm{jk}}$ \\
\hline XSY04 & $7.77^{\text {ghijk }}$ & $7.11^{\mathrm{kl}}$ & $-1.96^{\mathrm{hj} k \mathrm{j}}$ & $21.64^{\text {def }}$ & $18.48^{\mathrm{g}}$ \\
\hline XSY05 & $5.14^{\text {hijkl }}$ & $8.06^{\mathrm{jkl}}$ & $-4.17^{\mathrm{kl}}$ & $6.35^{\mathrm{gh}}$ & $39.27^{\mathrm{d}}$ \\
\hline XSY06 & $27.54^{\mathrm{c}}$ & $26.12^{\mathrm{d}}$ & $-1.62^{\mathrm{hijk}}$ & $32.15^{\mathrm{b}}$ & $41.25^{\mathrm{d}}$ \\
\hline XSY07 & $4.48^{\text {hijklm }}$ & $16.61^{\mathrm{fg}}$ & $-3.74^{\mathrm{kl}}$ & $18.29^{\text {def }}$ & $27.10^{\mathrm{e}}$ \\
\hline XSY08 & $6.46^{\mathrm{hijkl}}$ & $16.96^{\mathrm{fg}}$ & $9.10^{\mathrm{de}}$ & $18.77^{\text {def }}$ & $5.94^{\mathrm{klm}}$ \\
\hline XSY09 & $13.70^{\mathrm{fgh}}$ & $19.64^{\text {ef }}$ & $-0.26^{\mathrm{hijk}}$ & $8.26^{\mathrm{g}}$ & $13.53^{\mathrm{h}}$ \\
\hline XSY10 & $74.97^{\mathrm{a}}$ & $8.19^{\mathrm{jkl}}$ & $39.63^{\mathrm{b}}$ & $18.29^{\text {def }}$ & $6.80^{\mathrm{kmm}}$ \\
\hline XSY11 & $15.68^{\mathrm{fg}}$ & $7.76^{\mathrm{kl}}$ & $12.84^{\mathrm{d}}$ & $17.81^{\mathrm{ef}}$ & $5.28^{\operatorname{lmn}}$ \\
\hline XSY12 & $-2.11^{\operatorname{lm}}$ & $6.89^{1}$ & $5.19^{\mathrm{efg}}$ & $10.17^{\mathrm{g}}$ & $23.76^{\mathrm{f}}$ \\
\hline XSY13 & $17.66^{\text {def }}$ & $22.58^{\mathrm{e}}$ & $1.62^{\mathrm{gh}}$ & $0.13^{\mathrm{h}}$ & $45.22^{\mathrm{c}}$ \\
\hline XSY14 & $5.80^{\text {hijkl }}$ & $15.75^{\mathrm{gh}}$ & $8.38^{\mathrm{de}}$ & $16.86^{\mathrm{f}}$ & $17.16^{\mathrm{g}}$ \\
\hline XSY15 & $5.14^{\mathrm{hijk} k}$ & $12.64^{\mathrm{h}}$ & $1.20^{\text {ghij }}$ & $19.25^{\text {def }}$ & $67.00^{\mathrm{a}}$ \\
\hline XSY16 & $25.56^{\mathrm{cd}}$ & $18.34^{\mathrm{fg}}$ & $-7.57^{1}$ & $17.81^{\text {ef }}$ & $28.05^{\mathrm{e}}$ \\
\hline XSY17 & $16.34^{\mathrm{efg}}$ & $9.05^{\mathrm{ijk} 1}$ & $9.01^{\text {de }}$ & $7.78^{\mathrm{g}}$ & $4.62^{\mathrm{mn}}$ \\
\hline XSY18 & $-0.79^{\mathrm{jkm}}$ & $12.29^{\mathrm{h}}$ & $11.78^{\mathrm{d}}$ & $41.71^{\mathrm{a}}$ & $11.55^{\mathrm{h}}$ \\
\hline XSY19 & $-4.08^{\mathrm{m}}$ & $-0.15^{\mathrm{m}}$ & $-3.49^{\mathrm{k} 1}$ & $3.57^{\mathrm{gh}}$ & $2.31^{\mathrm{n}}$ \\
\hline XSY20 & $8.43^{\text {ghij }}$ & $18.13^{\mathrm{fg}}$ & $6.72^{\mathrm{ef}}$ & $7.97^{\mathrm{g}}$ & $8.78^{\mathrm{jk} k}$ \\
\hline XSY21 & $50.59^{\mathrm{b}}$ & $34.98^{c}$ & $17.73^{\mathrm{c}}$ & $-5.60^{\mathrm{ij}}$ & $18.02^{\mathrm{g}}$ \\
\hline \multicolumn{6}{|l|}{ Stems } \\
\hline XSJ01 & $24.24^{\text {cde }}$ & $11.99^{\mathrm{hij}}$ & $0.26^{\mathrm{hijk}}$ & $24.50^{\text {cde }}$ & $17.89^{\mathrm{g}}$ \\
\hline XSJ02 & $4.48^{\mathrm{hijk} k \mathrm{~m}}$ & $9.05^{\mathrm{j} \mathrm{jk} l}$ & $5.78^{\mathrm{efg}}$ & $-8.66^{\mathrm{j}}$ & $11.09^{\text {hij }}$ \\
\hline XSJ03 & $9.09^{\mathrm{fgh}}$ & $-2.74^{\mathrm{m}}$ & $6.38^{\text {ef }}$ & $28.33^{\mathrm{bc}}$ & $19.67^{\mathrm{g}}$ \\
\hline \multicolumn{6}{|l|}{ Fruits } \\
\hline XSG01 & $5.80^{\text {hijkl }}$ & $10.56^{\mathrm{ijkl}}$ & $2.38^{\text {fgh }}$ & $8.74^{\mathrm{g}}$ & $-0.73^{\circ}$ \\
\hline XSG02 & $10.41^{\text {fgh }}$ & $43.62^{\mathrm{b}}$ & $2.85^{\text {fgh }}$ & $-7.61^{j}$ & $-1.39^{\circ}$ \\
\hline Positive control ${ }^{\mathrm{b}}$ & $70.16^{\mathrm{a}}$ & $87.12^{\mathrm{a}}$ & $83.70^{\mathrm{a}}$ & $43.80^{\mathrm{a}}$ & $61.85^{\mathrm{b}}$ \\
\hline
\end{tabular}

${ }^{a}$ Each value is the mean of the 6 determinations from two experiments $(\mathrm{N}=6)$. Statistical analysis of the data was performed with the JMP software (DPS, 2000) using the Duncan HSD test for determining significant difference

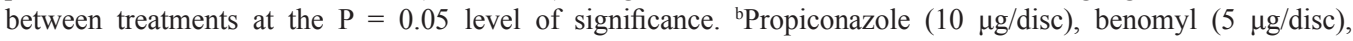
carbendazim $(20 \mu \mathrm{g} / \mathrm{disc})$.

\section{The antibacterial activities of the fermentation broth of endophytic fungi}

The antibacterial activities of the 26 isolates were detected in two bacteria. Half did not display any antibacterial activity against the two bacteria, while $34.6 \%$ showed activity against one pathogen and only $15.4 \%$ against two (Table 3 ). The inhibition zones ranged from 9 to $24 \mathrm{~mm}$, where the majority of inhibition zones of the isolates against the two pathogens were $10-14 \mathrm{~mm}$. Only the XSJ01 isolate exhibited strong antibacterial activity with more than a 20 -mm inhibition zone diameter. 


\begin{tabular}{|c|c|c|}
\hline \multirow[t]{2}{*}{ Part tested ${ }^{a}$} & \multicolumn{2}{|c|}{ Microorganisms tested } \\
\hline & P. solanacearum & R. solanacearum \\
\hline \multicolumn{3}{|l|}{ Leaves } \\
\hline XSY01 & - & - \\
\hline XSY02 & 11.34 & - \\
\hline XSY03 & - & 11.06 \\
\hline XSY04 & - & - \\
\hline XSY05 & - & 12.41 \\
\hline XSY06 & 13.18 & - \\
\hline XSY07 & - & 10.69 \\
\hline XSY08 & - & 11.60 \\
\hline XSY09 & 10.53 & 12.85 \\
\hline XSY10 & - & - \\
\hline XSY11 & 9.63 & - \\
\hline XSY12 & - & - \\
\hline XSY13 & 12.00 & 13.23 \\
\hline XSY14 & - & 10.65 \\
\hline XSY15 & - & - \\
\hline XSY16 & - & - \\
\hline XSY17 & - & - \\
\hline XSY18 & - & - \\
\hline XSY19 & - & 11.53 \\
\hline XSY 20 & - & - \\
\hline XSY21 & - & - \\
\hline \multicolumn{3}{|l|}{ Stems } \\
\hline XSJ01 & 23.19 & 23.89 \\
\hline XSJ02 & 11.48 & 12.07 \\
\hline XSJ03 & - & - \\
\hline \multicolumn{3}{|l|}{ Fruits } \\
\hline XSG01 & - & - \\
\hline XSG02 & - & - \\
\hline Positive control ${ }^{\mathrm{b}}$ & 26.57 & 23.32 \\
\hline Sterilized water & - & - \\
\hline
\end{tabular}

aiameter of inhibition zones (mm) including disc diameter of $6 \mathrm{~mm}$. “-” = not active. ${ }^{\mathrm{b}}$ Nystatin $(10 \mu \mathrm{g} / \mathrm{disc})$.

\section{DISCUSSION}

Endophytic fungi have been recognized as a repository of novel secondary metabolites, some of which have beneficial biological activities (Bills and Polishook, 1991; Strobel and Daisy, 2003). The results of the present study agree with these earlier findings. The results show that the fermentation broth of endophytic fungi of $C$. acuminata Decne. has broadspectrum antimicrobial activities against the mycelial growth of commercially important phytofungi and phytobacteria.

The endophytic fungi were identified and found to belong to 9 taxa (Table 1), including the most commonly isolated endophytic genera such as Colletotrichum, Alternaria and Pestalotiopsis, of which most are known to produce various bioactive products ( $\mathrm{Lu}$ et al., 2000; Li et al., 2001; Xiang et al., 2003). In contrast, some were rare endophytic genera such as Guignardia and Zythia, and these may be of potential practical value. Among the isolates, Diaporthe was the dominant genus with about $26.9 \%$ isolates belonging to it. Moreover, it was noted that different isolates in this genus exhibited different strengths of antimicrobial activities. The diversity of these isolates and of their active metabolites is worth further research.

Antifungal activities of plant endophytic fungi have been reported by a few groups (Fisher et al., 1984; Huang et al., 2001; Liu et al., 2001; Park et al., 2003). In the present 
study, the fermentation broths of 26 endophytic fungi were screened for antifungal activities in 5 pathogenic fungi, as an indication of their capability to produce secondary metabolites of potential therapeutic interest. Different isolates exhibited different antifungal spectra (Table 2). Among the 26 isolates, $7.7 \%$ displayed antifungal activity against only two pathogens, $3.8 \%$ against three pathogens, $57.7 \%$ against four, and 30.8\% against five. Moreover, the results show that a few isolates exhibited strong antifungal activity with growth inhibition rate ranging from 39.63 to $74.97 \%$ : XSY10 against $R$. solani and $P$. grisea, XSG02 against $G$. fujikuroi, XSY03 against G. zeae, and XSY15 against $F$. oxysporum f. sp. vasinfectum. The results indicate that the four isolates XSY10, XSY15, XSG02, and XSY03, of four different genera, exhibited different strengths of antifungal activity. They could be another potential source of bioactive antifungal agents, and their active metabolites are worth further research. Moreover, it is interesting to note that only the XSJ01 isolate exhibited strong antibacterial activity with a more than $20-\mathrm{mm}$ inhibition zone diameter. The XSJ01 strain was found to belong to Penicillium, which is known to produce various bioactive products, and that may account for the inhibitory effects of XSJ01 on two bacteria.

Our observations suggest that endophytic fungi of Camptotheca acuminata Decne. may have antimicrobial potential. The role of these endophytes is still unknown. Benefits to the host plant such as antagonism toward pathogenic fungi or decreased susceptibility to phytophagous insects could be speculated. Investigation of the interaction between Camptotheca acuminata Decne. and endophytic fungi would be the next direction for future research.

\section{ACKNOWLEDGMENTS}

Research supported by the Commonwealth Specialized Research Fund of China Agriculture (3-20) and Key Projects of University Natural Science of Anhui Province (Grant \#KJ2009A032Z).

\section{REFERENCES}

Agrios GN (2000). Plant Pathology. Academic Press, London.

Arnason JT, Philogene BJR and Morand P (1989). Insecticides of Plant Origin (ACS Symposium Series 387). American Chemical Society, Washington, DC.

Arnold AE, Maynard Z, Gilbert GS, Coley PD, et al. (2000). Are tropical fungal endophytes hyperdiverse? Ecol. Lett. 3: 267-274.

Bajwa R, Khalid A and Cheema TS (2003). Antifungal activity of allelopathic plant extracts III: Growth response of some pathogenic fungi to aqueous extract of Parthenium hysterophorus. Plant Pathol. J. 2: 145-156.

Bills GF and Polishook JD (1991). Microfungi from Carpinus caroliniana. Can. J. Bot. 69: 1477-1482.

Fisher PJ, Anson AE and Petrini O (1984). Antibiotic activity of some endophytic fungi from ericaceous plants. Bot. Helv. 94: 249-253.

Guo LD, Hyde KD and Liew ECY (2000). Identification of endophytic fungi from Livistona chinensis based on morphology and rDNA sequences. New Phytol. 147: 617-630.

Hayes WJ and Laws ER (1991). Handbook of Pesticide Toxicology. Vol. 1. Academic Press, New York.

Huang Y, Wang J, Li G, Zheng Z, et al. (2001). Antitumor and antifungal activities in endophytic fungi isolated from pharmaceutical plants Taxus mairei, Cephalataxus fortunei and Torreya grandis. FEMS Immunol. Med. Microbiol. 31: 163-167.

Lee SB, Milgroom MG and Taylor JW (1988). A rapid, high yield mini prep method for isolation of total genomic DNA from fungi. Fungal Genet. Newslett. 35: 23-24.

Li JY, Harper JK, Grant DM, Tombe BO, et al. (2001). Ambuic acid, a highly functionalized cyclohexenone with antifungal activity from Pestalotiopsis spp. and Monochaetia sp. Phytochemistry 56: 463-468. 
Liu CH, Zou WX, Lu H and Tan RX (2001). Antifungal activity of Artemisia annua endophyte cultures against phytopathogenic fungi. J. Biotechnol. 88: 277-282.

Lu H, Zou WX, Meng JC, Hu J, et al. (2000). New bioactive metabolites produced by Colletotrichum sp., an endophytic fungus in Artemisia annua. Plant Sci. 151: 67-73.

NCCLS (National Committee for Clinical Laboratory Standards) (2003). Performance Standards for Antimicrobial Disk Susceptibility Test. Approved standard, 6th edn. Wayne, PA.

Omacini M, Chaneton EJ, Ghersa CM and Muller CB (2001). Symbiotic fungal endophytes control insect host-parasite interaction webs. Nature 409: 78-81.

Park JH, Park JH, Choi GJ, Lee SW, et al. (2003). Screening for antifungal endophytic fungi against six plant pathogenic fungi. Mycobiology 31: 179-182.

Strobel G and Daisy B (2003). Bioprospecting for microbial endophytes and their natural products. Microbiol. Mol. Biol. Rev. 67: 491-502.

Xiang Y, Liu J, Lu AG and Cui JX (2003). Structure identification for compound separated and purified from taxoidsproduced endophytic fungi (Alternaria. alternata var. taxi 101). J. Forestry Res. 14: 217-220 